\title{
Thermal and Fire Properties of Medium-density Fiberboard Prepared with Huntite/hydromagnesite and Zinc Borate
}

\author{
Derya Ustaömer * and Umut Emre Başer \\ Effects of mineral-based fire retardants were investigated relative to the \\ thermal and fire properties of medium-density fiberboard (MDF) via \\ thermogravimetric analysis (TGA), limiting oxygen index (LOI), and \\ thermal conductivity testing. Mineral-based chemicals containing huntite \\ /hydromagnesite and zinc borate (ZB) were used at different \\ concentrations. Changes in all values were observed depending on the \\ type and concentration of chemicals. According to TGA evaluation, the \\ residual weights in the MDF samples manufactured with mineral-based \\ chemicals were higher than the residual weight in the control MDF sample. \\ Limiting oxygen index testing results showed higher values for the MDF \\ samples manufactured with mineral-based chemicals than for the control \\ sample. The LOI values increased with the increment of chemical \\ concentration, and the highest value was observed in group B12. The \\ thermal conductivity trends of the MDF samples varied depending on the \\ type and concentration of chemicals. Generally, the thermal conductivity \\ values of the MDF samples manufactured with chemicals were found to \\ be higher than the value of the control. These results suggested that these \\ chemicals with various combinations should be evaluated as fire \\ retardants for wood and wood-based panel industry.
}

Keywords: Fire resistance; Huntite/hydromagnesite; MDF; Thermal conductivity; Zinc borate

Contact information: Department of Forest Industry Engineering, Karadeniz Technical University, 61080, Trabzon, Turkey; *Corresponding author: uderya@ktu.edu.tr

\section{INTRODUCTION}

Recently, there has been a notable increase in the utilization of wood and woodbased composites in many areas, including residential and non-residential construction. However, wood-based materials have some limitations, such as their inherent flammability. Therefore, the use of these materials can cause hazardous fires (Lowden and Hull 2013).

Chemical applications for wooden materials have increased notably. These applications improve the mechanical, biological, physical, and fire resistance properties of wooden materials (Baysal et al. 2007). Various fire retardants containing compounds of halogen, boron, phosphorus, aluminum, magnesium are widely used for combustible materials to improve their fire retardant properties (Çavdar 2020). These fire retardants can be utilized alone, together, or combined with various additives (Liu et al. 2016).

An important class of fire retardants is mineral fillers, and they have inherently sustainable attributes (Hull et al. 2011). Huntite $\left[\mathrm{Mg}_{3} \mathrm{Ca}\left(\mathrm{CO}_{3}\right)_{4}\right]$ and hydromagnesite $\left[\mathrm{Mg}_{5}\left(\mathrm{CO}_{3}\right)_{4}(\mathrm{OH})_{2} \cdot 4\left(\mathrm{H}_{2} \mathrm{O}\right)\right]$ are carbonate minerals (Kangal et al. 2005). Their mixtures are more eco-friendly and greener chemicals (Hollingbery and Hull 2012). In addition, they have other advantages such as low combustion properties, low smoke generation, non- 
halogenated, environmentally safe, non-corrosiveness and recyclability (Atay and Çelik 2010). The mixtures of huntite and hydromagnesite have important industrial uses and especially employ as fire retardants for polymers by contributing the reduction in their flammability properties. They have been used in place of magnesium hydroxide and aluminium hydroxide, which are the most widely used of metal hydroxides, in various material applications as fire retardants. Turkey has mixture of hydromagnesite/huntite reserves, which are reported as the largest reserves in the world (Hollingbery and Hull 2010).

The use of huntite/hydromagnesite as mineral-based chemicals for various composites and other materials has been investigated by many researchers (Toure et al. 1996; Atay and Çelik 2010, 2013, 2016; Şen et al. 2014; Dike et al. 2017; Güler et al. 2017; Savas et al. 2018; Camlibel et al. 2019). Several studies were also carried out using these minerals as fire retardant chemicals for forest fire, some forest species and wood parts (Liodakis et al. 2008, 2009, 2013; Liodakis and Tsoukala 2010). However, there is limited information about the use of these chemicals as fire retardants for wood-based materials. Başer et al. (2017) reported in another part of their study that the huntite/hydromagnesite and ZB had positive effect on the biological properties of MDF samples. They suggested that these chemicals could be used to protect wooden materials against biological deterioration as potential protection chemicals.

Boron-containing fire retardant chemicals are cheaper and less toxic than traditional fire retardants. Zinc borate $(\mathrm{ZB})$ is a particularly important borate compound that is mainly used with other fire retardants as a synergistic chemical (Fang et al. 2013). It is one of the effective flame retardants, which is used as a synergistic additive with mineral-based flame retardants for the applications of different polymer materials to enhance their flame retardancy (Zhang et al. 2012; Dike et al. 2017). It is also used as a smoke-suppressant and afterglow-suppressant additive (Shen et al. 2008).

The aims of this study were: (i) to determine the effects of huntite/hydromagnesite and $\mathrm{ZB}$ on the thermal and fire properties of medium-density fiberboard (MDF) manufactured with these chemicals; and (ii) to investigate the potential of huntite/hydromagnesite, which are generally used for polymer applications, as fire retardant chemicals for wood and wood-based panel industry.

\section{EXPERIMENTAL}

\section{Materials}

In this study, beech fibers were used as the raw material. The fibers and urea formaldehyde (UF) were supplied by Kastamonu Integrated Wood Industry and Trade Inc. (Gebze, Turkey). Two mineral-based commercial products under the trade name UltraCarb 1250 and UltraCarb LH15 were supplied by Likya Minerals (İzmir, Turkey) and used as fire-retardant chemicals. These two chemicals contain a mixture of huntite and hydromagnesite at different ratios. Zinc borate was also used as a fire retardant chemical.

\section{Experimental Parameters}

The experimental parameters used in this study are shown in Table 1. 
Table 1. Experimental Parameters

\begin{tabular}{|c|c|c|c|c|}
\hline \multirow{2}{*}{ Panel Group } & \multirow{2}{*}{ Chemicals } & \multicolumn{3}{|c|}{ Chemical Rates } \\
\hline & & $4 \%$ & $8 \%$ & $12 \%$ \\
\hline A & U1 & A4 & A8 & $\mathrm{A} 12$ \\
\hline $\mathrm{B}$ & U2 & B4 & B8 & B12 \\
\hline $\mathrm{C}$ & $\mathrm{U} 1+\mathrm{ZB}(50+50 \%)$ & $\mathrm{C} 4$ & C8 & $\mathrm{C} 12$ \\
\hline $\mathrm{D}$ & U2 +ZB (50+50\%) & D4 & D8 & D12 \\
\hline Control & \\
\hline \multicolumn{5}{|c|}{$\begin{array}{l}\text { *Chemical U1: "trade product (UltraCarb 1250)" and Chemical U2: "trade product } \\
\text { (UltraCarb LH15)" consist of a mixture of huntite and hydromagnesite. } \\
\star \star \\
\text { mixture, Chemical U1 p2 primarily contains more hydromagnesite rate than huntite rate } \\
\text { in the mixture. }\end{array}$} \\
\hline
\end{tabular}

\section{Methods}

MDF panel preparation

At the beginning of panel preparation, wood fibers were dried using a laboratory oven until reaching approximately $2 \%$ to $3 \%$ moisture content. Next, mineral-based chemicals were prepared at concentrations of $4 \%, 8 \%, 12 \%$ and added to the ureaformaldehyde resin. Then, the resin was sprayed on the fibers and the mats were formed. After that, the panel mats were pressed using a computer-controlled press (Cemilusta Hot Press; Cemilusta Wood Working Machinery Ind. Inc., Istanbul, Turkey) at a temperature of $180^{\circ} \mathrm{C}$ for $7 \mathrm{~min}$. The MDF panels were kept in a climate-controlled room until testing.

\section{Limiting oxygen index (LOI)}

Limiting oxygen index measurements of MDF samples were carried out according to ASTM D2863-19 (2013) using a limiting oxygen index chamber (Dynisco, Franklin, MA, USA). The MDF samples were placed in a vertical glass column. These samples were then ignited by a flame and burned. After burning, the minimum oxygen concentrations of the samples were calculated. Five MDF samples with dimensions of $15 \mathrm{~mm}$ x $100 \mathrm{~mm} \times 10$ $\mathrm{mm}$ were tested for each group.

\section{Thermogravimetric analysis (TGA)}

Thermogravimetric analysis was performed to determine the weight losses of the MDF samples using a thermal analyzer instrument (TGA 6000; PerkinElmer, Waltham, MA,USA) at a heating rate of $10{ }^{\circ} \mathrm{C} / \mathrm{min}$ under a dynamic nitrogen atmosphere with a 20 $\mathrm{mL} / \mathrm{min}$ flow rate. For this analysis, powders were prepared from the MDF panels and placed in the TGA instrument to calculate weight losses.

\section{Thermal conductivity}

Thermal conductivity measurements of the MDF samples were carried out according to ASTM C518-17 (2004) using a LaserComp FOX-314 heat flow meter instrument which measures the steady-state heat transfer through flat materials. The panel samples with dimension of $30 \mathrm{~cm} \times 30 \mathrm{~cm} \times 1 \mathrm{~cm}$ were used for measurements. 


\section{RESULTS AND DISCUSSION}

\section{Limiting Oxygen Index}

The LOI values of MDF panel samples are presented in Fig. 1 and Table 2. Some observations are also presented in Table 2. Figure 1 shows that the LOI values of MDF panels manufactured with mineral compounds increased notably as the concentration of chemicals increased. The values ranged from $29.8 \%$ to $35.2 \%$ (Table 2). The lowest LOI value was observed for control group $(29.8 \%)$. The second lowest LOI value was obtained from group A4 (31.5\%), the highest LOI value was observed for group B12 (35.2\%) among LOI values of all groups. The LOI values of the groups A, B, C, and D were found notably higher than the value of control group.

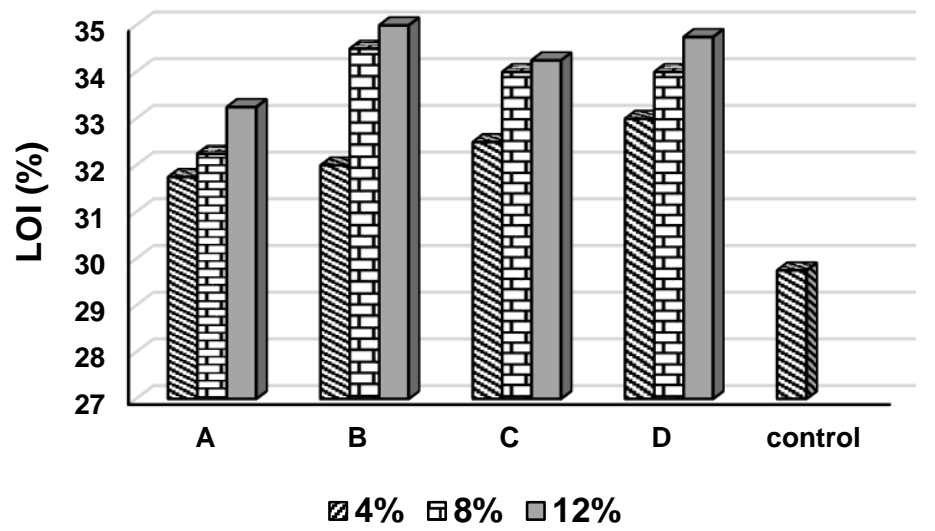

Fig. 1. The LOI levels of MDF samples

As can be seen from Fig. 1 and Table 2, especially, groups B and D had higher LOI levels than the groups A and C. At the same time, these results indicated that the use of chemical U2 alone and in combination with ZB provided more improvement on the LOI values, compared to the use of chemical U1 alone and in combination with ZB. This also means that the more hydromagnesite rate in the mixture of hydromagnesite/huntite showed more positive effect on the LOI levels. These results showed that the fire resistance of MDF samples improved with the use of these chemicals.

Table 2. The LOI Values and Observation Results

\begin{tabular}{|c|c|c|}
\hline Panel Groups & LOI (\%) & Observations \\
\hline A4 & 31.50 & white layer, low smoke \\
\hline A8 & 32.25 & burned by charring, low smoke \\
\hline A12 & 33.75 & charred, white layer, no smoke \\
\hline B4 & 32.50 & slow flame, burned properly, low smoke \\
\hline B8 & 34.10 & burned by charring, no smoke \\
\hline B12 & 35.25 & burned by charring, no smoke \\
\hline C4 & 32.50 & slow flame, burned properly, low smoke \\
\hline C8 & 33.15 & burned slowly, no smoke \\
\hline C12 & 34.25 & burned properly, no smoke \\
\hline D4 & 33.25 & charred, no smoke \\
\hline D8 & 34.25 & charred, no smoke \\
\hline D12 & 35.00 & charred, no smoke \\
\hline Control & 29.75 & There was smoke, burned quickly \\
\hline
\end{tabular}


During LOI testing, some visual observations were recorded to supplement the measured changes in the LOI values of MDF samples (Table 2). Generally, MDF samples with mineral-based compounds showed remarkably slow burning and the formation of char. In addition, while smoke generation was observed in the control group, low smoke or no smoke was observed in the groups A, B, C, and D. The char residue of the samples increased with increasing chemical concentration. Further, the surface layer of some LOI samples manufactured with mixture of huntite/hydromagnesite turned to a white color during combustion.

Some researchers have reported that LOI values in their studies increased with the use of huntite/hydromagnesite and fire resistance of studied materials improved (Liodakis et al. 2009; Atay and Çelik 2010; Dike et al. 2017).

\section{TGA Evaluation}

Thermogravimetric (TG) analysis results are given in Table 3, and the comparative TGA curves of MDF samples dependent on concentration for every group are shown in Fig. 2.

Table 3. Thermogravimetric Analysis Results

\begin{tabular}{|c|c|c|c|c|}
\hline Panel Group & $T_{\text {in }}\left({ }^{\circ} \mathrm{C}\right)$ & $T_{\max }\left({ }^{\circ} \mathrm{C}\right)$ & $T_{\text {end }}\left({ }^{\circ} \mathrm{C}\right)$ & Residual Weight $(\%)$ \\
\hline A4 & 310.19 & 360.46 & 381.98 & 23.61 \\
\hline A8 & 278.01 & 291.30 & 338.88 & 21.23 \\
\hline A12 & 296.99 & 362.53 & 381.63 & 21.30 \\
\hline B4 & 296.82 & 360.95 & 386.39 & 23.02 \\
\hline B8 & 297.82 & 364.48 & 385.62 & 22.55 \\
\hline B12 & 286.81 & 359.23 & 386.30 & 21.95 \\
\hline C4 & 289.69 & 362.79 & 387.07 & 22.77 \\
\hline C8 & 290.16 & 363.18 & 387.85 & 21.34 \\
\hline C12 & 292.10 & 363.36 & 386.60 & 22.74 \\
\hline D4 & 289.57 & 362.09 & 388.15 & 20.30 \\
\hline D8 & 290.86 & 361.51 & 387.26 & 20.89 \\
\hline D12 & 293.61 & 363.66 & 387.74 & 21.80 \\
\hline Control & 266.54 & 269.52 & 285.90 & 12.09 \\
\hline
\end{tabular}

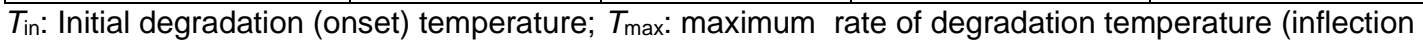
point); $T_{\text {end: Final degradation (endset) temperature }}$

Figure 2 shows that, a small decrease in the weights of MDF samples was observed at low temperatures (especially, between $100{ }^{\circ} \mathrm{C}$ to $150{ }^{\circ} \mathrm{C}$ ). This was likely due to the removal of water from the samples. At this stage, remarkable changes were not observed as expected and only small changes occurred in the MDF samples. As known, at the temperatures between $100{ }^{\circ} \mathrm{C}$ and $200{ }^{\circ} \mathrm{C}$, wood material starts to dehydrate and various products such as noncombustible gases, liquids, and water vapor, appear in this step (Dietenberger and Hasburgh 2016).

In this study, decreases in the MDF sample weights began after $200{ }^{\circ} \mathrm{C}$, and important decreases were observed between $265{ }^{\circ} \mathrm{C}$ to $390{ }^{\circ} \mathrm{C}$ depending on the type and concentration of chemicals. This phenomenon was attributed to the changes in the chemical structure of wood, when wood material heated at elevated temperatures. The thermal degradation starts in the three main components (hemicellulose, cellulose, lignin) of wood depending on the temperature. First, hemicellulose starts to degrade followed by cellulose and lignin (Çavdar et al. 2010; Lowden and Hull 2013). It was reported that the thermal 
degradation temperatures and char residue amount of studied material samples increased after degradation due to the use of fire retardant chemicals (Donmez Cavdar et al. 2016). It was stated that, the mixture of huntite/hydromagnesite decomposes endothermically, and carbon dioxide, water are released by this endothermic reaction. The decomposition for their mixture occurs over a wide temperature range which starts at about $220{ }^{\circ} \mathrm{C}$ and is complete by about $740{ }^{\circ} \mathrm{C}$ (Hollingbery and Hull 2010).

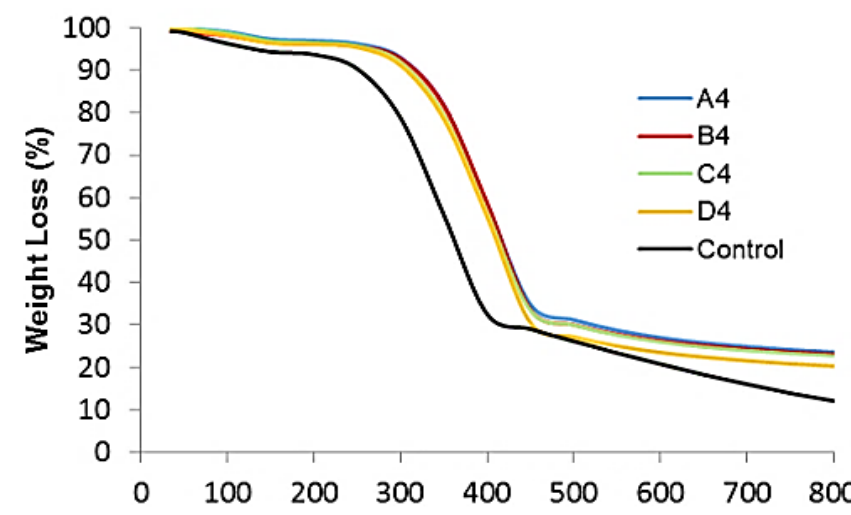

Temperature $\left({ }^{\circ} \mathrm{C}\right)$

(a) Groups A, B, C, and D (4\%)

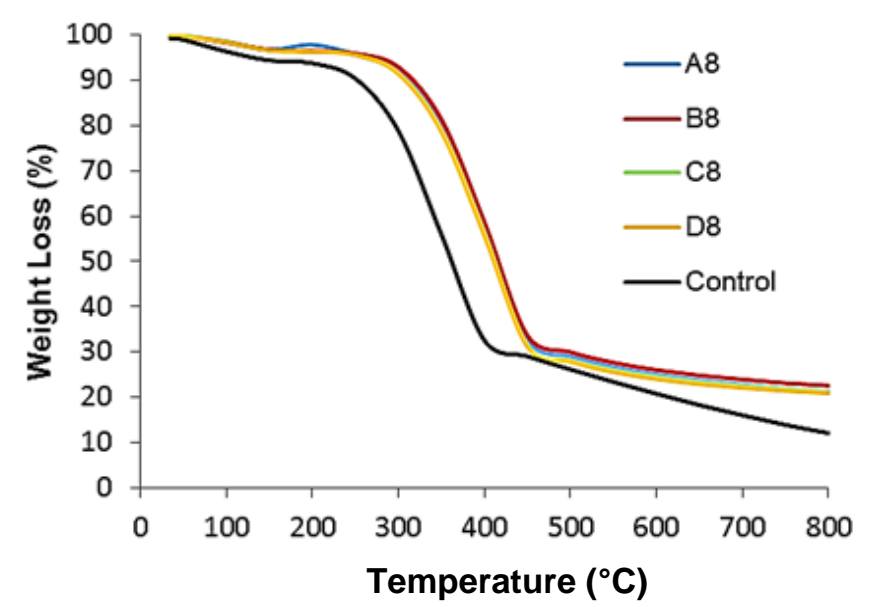

(b) Groups A, B, C, and D (8\%)

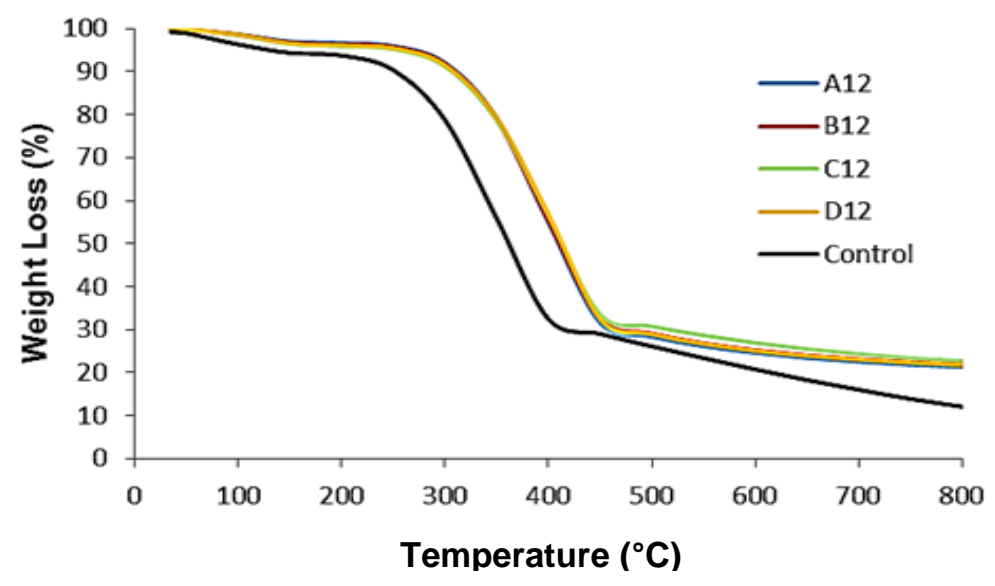

(c) Groups A, B, C, and D (12\%)

Fig. 2. The TGA curves of groups $A, B, C$, and $D$ 
Table 3 includes the $T_{\text {in }}$ (onset), $T_{\max }$, and $T_{\text {end }}$ (endset) temperatures. According to Table 3, the initial degradation temperatures (the temperatures at which samples started to decompose) ranged from $266.5{ }^{\circ} \mathrm{C}$ to $310.2{ }^{\circ} \mathrm{C}$. These temperatures for groups $\mathrm{A}, \mathrm{B}, \mathrm{C}$, and $\mathrm{D}$ with chemicals were found to be higher than for that of control group. $T_{\max }$ values of samples were found among $269.5{ }^{\circ} \mathrm{C}$ and $364.5^{\circ} \mathrm{C}$. The highest $T_{\max }$ value was found for group B8. The lowest $T_{\max }$ value was found for the control group. Furthermore, all groups manufactured with mineral-based chemicals had higher endset temperatures than the control group. These temperatures ranged from $285.9{ }^{\circ} \mathrm{C}$ to $388.2{ }^{\circ} \mathrm{C}$. Table 3 also shows that the residual weights at around $800{ }^{\circ} \mathrm{C}$ of all groups with chemicals notably increased, and all values were found higher than that of the control group. The highest residual weight $(23.6 \%)$ was found for group A4. This value was almost double the lowest residual weight $(12.1 \%)$ obtained from control group. Even though the residual weights of groups $\mathrm{A}, \mathrm{B}$, and $\mathrm{C}$ did not show an increment trend with the increasing concentration of chemicals, the residual weight values of group D slightly increased with increasing concentration of chemical. Additionally, when comparing the samples of groups $\mathrm{C}$ and $\mathrm{D}$ manufactured with chemicals containing $\mathrm{ZB}$ with huntite and hydromagnesite together, it was seen that the residual weights of group $\mathrm{C}$ manufactured with $\mathrm{U} 1+\mathrm{ZB}$ chemicals having more huntite rate than hydromagnesite in the mixture were higher than those of group $\mathrm{D}$ manufactured with $\mathrm{U} 2+\mathrm{ZB}$ chemicals having more hydromagnesite rate than huntite in the mixture. Considerable synergistic effect with the use of $\mathrm{ZB}$ were not obtained in the groups $\mathrm{C}$ and D. Especially the lower residual weights were found for group D with ZB.

The TGA curves (Fig. 2) also show that the residual weights of the MDF samples manufactured with chemicals exhibited an increasing trend and thermal stability improved depending on the type and concentration of chemicals.

\section{Thermal Conductivity}

The thermal conductivity results of MDF samples are shown in Fig. 3. The thermal conductivity values of MDF samples changed depending on the type and concentration of chemical. It was stated that thermal conductivity of wood based composite materials changes depend on various parameters including wood species, fiber direction, resin type, composite thickness, and additives (Demirkır et al. 2013).

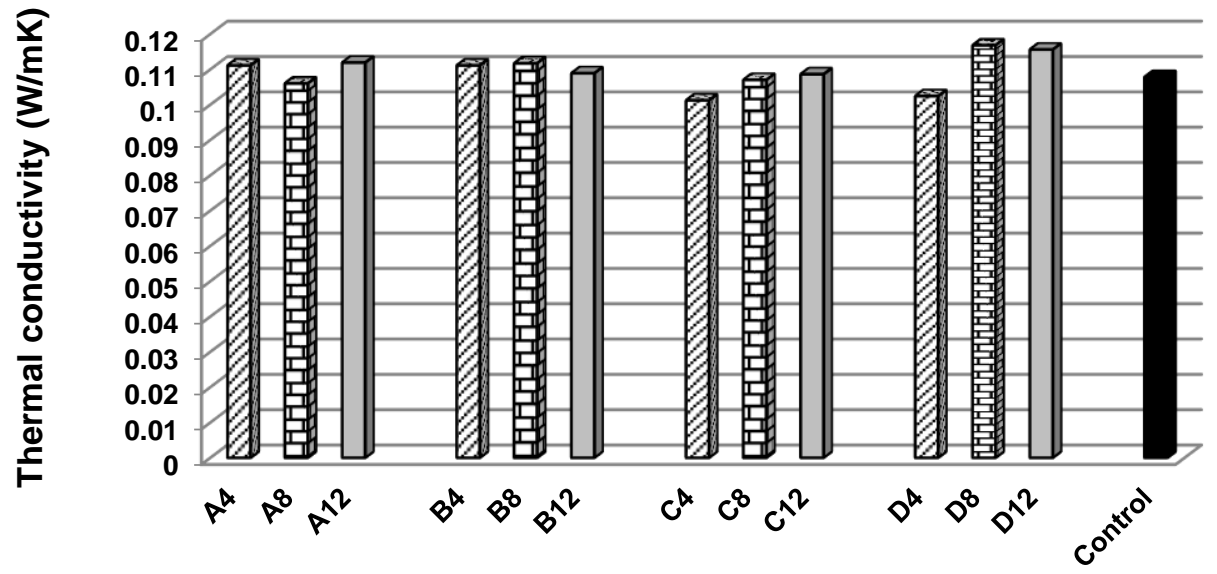

Fig. 3. The thermal conductivity of MDF samples 
In this study, the thermal conductivity values ranged from $0.1012 \mathrm{~W} / \mathrm{mK}$ to 0.1168 $\mathrm{W} / \mathrm{mK}$. The value of the control panel sample was determined to be $0.1078 \mathrm{~W} / \mathrm{mK}$. As can be seen in Fig. 3, generally, most values of groups A, B, C, and D were found to be higher than the control value and an increasing trend was observed in these groups, especially, depending on the concentration of chemicals. It was reported that the incorporation of noncombustible mineral fillers to a polymer decrease its flammability and increase the thermal conductivity and heat capacity (Hull et al. 2011).

Although the highest values of $0.1168 \mathrm{~W} / \mathrm{mK}$ and $0.1156 \mathrm{~W} / \mathrm{mK}$ were found for groups D8 and D12, respectively, the lowest thermal conductivity values of $0.1012 \mathrm{~W} / \mathrm{mK}$ and $0.1024 \mathrm{~W} / \mathrm{mK}$ were found for groups C4 and D4, respectively. In general, the thermal conductivity values of some MDF panels were found slightly close to each other and distinct differences were not seen for these groups. This could be due to the effect of various production parameters.

\section{CONCLUSIONS}

1. All mineral-based chemicals had remarkable effects, particularly on limiting oxygen index (LOI) and thermogravimetric analysis (TGA) values.

2. The residual weights of the medium-density fiberboard (MDF) samples prepared with the chemicals were found to be higher than the residual weight of the control sample.

3. The LOI values increased with increasing chemical concentration, and group B12 had the highest LOI value.

4. Generally, the thermal conductivity values of MDF panels manufactured with the chemicals were found higher than that of the control panel.

5. The results suggest that huntite/hydromagnesite minerals, which are widely known as fire retardants for plastic materials, also have considerable effects on the fire properties of MDF panels. Therefore, they can be used alone or in combination with other fire retardants as potential chemical agents in the wood and wood-based panel industry.

\section{ACKNOWLEDGEMENTS}

The authors thank Assoc. Prof. Dr. Ayfer Dönmez Çavdar, Assoc. Prof. Dr. Emrah Peşman, Lecturer Uğur Aras and Ress. Assist. Dr. Aydın Demir for their contributions and thank Prof. Dr. Hülya Kalaycıoğlu and Prof. Dr. İsmail Aydın for providing use of their laboratory equipment. The authors also thank the Likya Minerals Company (İzmir,Turkey) and Kastamonu Integrated Wood Company and Trade Inc. (Gebze,Turkey) for providing study materials. This study was presented as part of the Master's thesis of Umut Emre Başer under the supervision of Assist. Prof. Dr. Derya Ustaömer. 


\section{REFERENCES CITED}

ASTM C518-17 (2004). "Standard test method for steady-state heat flux measurements and thermal transmission properties by means of the heat flow meter apparatus," ASTM International, West Conshohocken, PA, www.astm.org

ASTM D2863-19 (2013). "Standard test method for measuring the minimum oxygen concentration to support candle-like combustion of plastics (oxygen index)," ASTM International, West Conshohocken, PA, www.astm.org

Atay, H. Y., and Çelik, E. (2010). "Use of Turkish huntite/hydromagnesite mineral in plastic materials as a flame retardant," Polym. Compos. 31(10), 1692-1700. DOI: $10.1002 /$ pc.20959

Atay, H. Y., and Çelik, E. (2013). "Mechanical properties of flame-retardant huntite and hydromagnesite-reinforced polymer composites," Polym-Plast. Technol. Eng. 52(2), 182-188. DOI: 10.1080/03602559.2012.735310

Atay, H. Y., and Çelik, E. (2016). "Flame retardant properties of boric acid and antimony oxide accompanying with huntite and hydromagnesite in the polymer composites," Polym. Polym. Compos. 24(6), 419-428, DOI: 10.1177/096739111602400605

Başer, U. E , Ustaömer, D., Özgenç, Ö. (2017), "Decay resistance of MDF manufactured with huntite-hydromagnesite and zinc borate," $48^{\text {th }}$ Annual Meeting of the International Research Group on Wood Protection, Ghent, Belgium, IRG/WP 1730710

Baysal, E., Yalinkilic, M. K., Altinok, M., Sonmez, A., Peker, H., and Colak, M. (2007). "Some physical, biological, mechanical, and fire properties of wood polymer composite (WPC) pretreated with boric acid and borax mixture," Constr. Build. Mater. 21(9), 1879-1885. DOI: 10.1016/j.conbuildmat.2006.05.026

Camlibel, N. O., Avinc, O., Arik, B., Yavas, A., and Yakin, I. (2019). "The effects of huntite-hydromagnesite inclusion in acrylate-based polymer paste coating process on some textile functional performance properties of cotton fabric," Cellulose 26(2), 1367-1381. DOI: 10.1007/s10570-018-1924-y

Çavdar, A. D., Ertaş, M., Kalaycıoğlu, H., and Alma, M. H. (2010). "Some properties of thin medium density fiberboard panels treated with sunflower waste oil vapor," Mater. Des. 31(5), 2561-2567. DOI: 10.1016/j.matdes.2009.11.035

Çavdar, A. D. (2020). "Effect of zeolite as filler in medium density fiberboards bonded with urea formaldehyde and melamine formaldehyde resins," J. Build. Eng. 27, DOI: 10.1016/j.jobe.2019.101000

Demirkir, C., Colak, S., and Aydin, I. (2013). "Some technological properties of woodstyrofoam composite panels," Composites, Part B. 55, 513-517. DOI:

10.1016/j.compositesb.2013.07.024

Dietenberger, M. A., and Hasburgh, L. E. (2016). "Wood products: Thermal degradation and fire," Reference Module in Materials Science and Materials Engineering, 1-8. DOI: $10.1016 / \mathrm{b} 978-0-12-803581-8.03338-5$

Dike, A. S., Tayfun, U., and Dogan, M. (2017). "Influence of zinc borate on flame retardant and thermal properties of polyurethane elastomer composites containing huntite-hydromagnesite mineral," Fire Mater. 41(7), 890-897. DOI: 10.1002/fam. 2428

Donmez Cavdar, A., Kalaycioglu, H., and Mengeloğlu, F. (2016). “Technological properties of thermoplastic composites filled with fire retardant and tea mill waste fiber," J. Compos. Mater. 50(12), 1627-1634. DOI: 10.1177/0021998315595113 
Fang, Y., Wang, Q., Guo, C., Song, Y., and Cooper, P. A. (2013). "Effect of zinc borate and wood flour on thermal degradation and fire retardancy of polyvinyl chloride (PVC) composites," J. Anal. Appl. Pyrolysis 100, 230-236. DOI: 10.1016/j.jaap.2012.12.028

Guler, T., Tayfun, U., Bayramli, E., and Dogan, M. (2017). "Effect of expandable graphite on flame retardant, thermal and mechanical properties of thermoplastic polyurethane composites filled with huntite\&hydromagnesite mineral," Thermochim. Acta 647, 70-80. DOI: 10.1016/j.tca.2016.12.001

Hollingbery, L. A., and Hull, T. R. (2010). "The fire retardant behaviour of huntite and hydromagnesite - A review," Polym. Degrad. Stab. 95(12), 2213-2225.

DOI: 10.1016/j.polymdegradstab.2010.08.019

Hollingbery, L. A., and Hull, T. R. (2012). "The fire retardant effects of huntite in natural mixtures with hydromagnesite," Polym. Degrad. Stab. 97(4), 504-512. DOI: 10.1016/j.polymdegradstab.2012.01.024

Hull, T. R., Witkowski, A., and Hollingbery, L. (2011). "Fire retardant action of mineral fillers," Polym. Degrad. Stab. 96(8), 1462-1469. DOI: 10.1016/j.polymdegradstab.2011.05.006

Kangal, O., Firat, C., and Güney, A. (2005). "Flotation properties of unusual carbonates: huntite and hydromagnesite," Miner. Eng. 18(6), 631-634. DOI:

10.1016/j.mineng.2004.09.006

Liodakis, S., Antonopoulos, I., Agiovlasitis, I. P., and Kakardakis, T. (2008). "Testing the fire retardancy of Greek minerals hydromagnesite and huntite on WUI forest species Phillyrea latifolia L.” Thermochim. Acta 469(1-2), 43-51.

DOI:10.1016/j.tca.2007.12.010

Liodakis, S., Antonopoulos, I., and Tsapara, V. (2009). "Forest fire retardancy evaluation of carbonate minerals using DTG and LOI," J. Therm. Anal. Calorim. 96(1), 203-209. DOI: $10.1007 / \mathrm{s} 10973-008-9378-3$

Liodakis, S., and Tsoukala, M. (2010). "Environmental benefits of using magnesium carbonate minerals as new wildfire retardants instead of commercially available, phosphate-based compounds," Environ. Geochem. Health 32(5), 391-399. DOI:10.1007/s10653-009-9283-0

Liodakis, S., Tsapara, V., Agiovlasitis, I. P., and Vorisis, D. (2013). “Thermal analysis of Pinus sylvestris L. wood samples treated with a new gel-mineral mixture of shortand long-term fire retardants," Thermochim. Acta 568, 156-160. DOI: 10.1016/j.tca.2013.06.011

Liu, J., Chen, T., Xie, Y., Wei, Q., Chen, Y., Rao, J., Niu, M., and Wang, X. A. (2016). "Fire performance of ultra-low density fiberboard (ULDF) with complex fireretardants," BioResources 11(4), 10261-10272. DOI: 10.15376/biores.11.4.1026110272

Lowden, L. A., and Hull, T. R. (2013). "Flammability behaviour of wood and a review of the methods for its reduction," Fire Sci. Rev. 2(1), 4. DOI: 10.1186/2193-0414-2-4

Savas, L. A., Arslan, C., Hacioglu, F., and Dogan, M. (2018). "Effect of reactive and nonreactive surface modifications and compatibilizer use on mechanical and flameretardant properties of linear low-density polyethylene filled with huntite and hydromagnesite mineral," J. Therm. Anal. Calorim. 134(3), 1657-1666. DOI: 10.1007/s10973-018-7378-5

Shen, K. K., Kochesfahani, S., and Jouffret, F. (2008). "Zinc borates as multifunctional polymer additives," Polym. Adv. Technol. 19(6), 469-474. DOI: 10.1002/pat.1119 
Şen, F., Madakbaş, S., and Kahraman, M. V. (2014). "Preparation and characterization of polyaniline/Turkish huntite-hydromagnesite composites," Polym. Compos. 35(3), 456-460. DOI: 10.1002/pc.22681

Toure, B., Cuesta, J. M. L., Gaudon, P., Benhassaine, A., and Crespy, A. (1996). "Fire resistance and mechanical properties of a huntite/hydromagnesite/antimony trioxide/decabromodiphenyl oxide filled PP-PE copolymer," Polym. Degrad. Stab. 53(3), 371-379. DOI: 10.1016/0141-3910(96)00100-0

Zhang, R., Huang, H., Yang, W., Xiao, X., and Hu, Y. (2012). "Effect of zinc borate on the fire and thermal degradation behaviors of a poly (3-hydroxybutyrate-co-4hydroxybutyrate)-containing intumescent flame retardant," J. Appl. Polym. Sci. 125(5), 3946-3955. DOI: 10.1002/app.36533

Article submitted: February 20, 2020; Peer review completed: May 3, 2020; Revised version received and accepted: May 30, 2020; Published: June 16, 2020.

DOI: $10.15376 /$ biores. 15.3.5940-5950 